\title{
Pass/Fail and Discretionary Grading: A Snapshot of Their Influences on Learning
}

\author{
Sherri Melrose \\ Centre for Nursing and Health Studies, Athabasca University, Athabasca, Alberta, Canada \\ Email: sherrim@athabascau.ca
}

How to cite this paper: Melrose, S. (2017) Pass/Fail and Discretionary Grading: A Snapshot of Their Influences on Learning. Open Journal of Nursing, 7, 185-192. https://doi.org/10.4236/ojn.2017.72016

Received: December 24, 2016

Accepted: February 10, 2017

Published: February 14, 2017

Copyright $\odot 2017$ by author and Scientific Research Publishing Inc. This work is licensed under the Creative Commons Attribution International License (CC BY 4.0).

http://creativecommons.org/licenses/by/4.0/

\begin{abstract}
This article provides a snapshot of pass/fail and discretionary grading approaches, highlighting the advantages and disadvantages of each. Normreferenced and criterion-referenced grading practices and their associations with learning are identified. A brief historical backdrop illustrates how grading practices have evolved. The inherent subjectivity of grading is emphasized. Pass/fail grading supports intrinsic motivation and self-direction, but limits opportunities for recognizing excelling students. Discretionary grading, which includes letter $(\mathrm{F}-$ to $\mathrm{A}+)$ and numeric $(0 \%$ to $100 \%)$ representations, supports extrinsic motivation and self-improvement, but promotes unhealthy competition. Both approaches have merit and can effectively measure student achievement in nursing education programs.
\end{abstract}

\section{Keywords}

Pass/Fail Grading, Discretionary Grading, Norm-Referenced Grading, Criteria-Referenced Grading

\section{Introduction}

Acquiring the knowledge, skills and attitudes nursing students need to demonstrate competence in their practice is a complex process. Few topics have generated more discussion than the influences that grades can have on student learning. Yet, existing research offers limited evidence that either pass/fail or discretionary grades do adequately measure and influence learning.

Two grading approaches are typically implemented in nursing education programs. The first approach, where students are assigned pass/fail or satisfactory/ unsatisfactory, evaluates overall understanding and competence [1] [2] [3]. The second approach, discretionary grading, where students are assigned letters such as $\mathrm{F}-$ to $\mathrm{A}+$ or numerical values between $0 \%$ and $100 \%$ integrates more discriminative information [4]. 
Lee Cronbach's seminal definition of learning emphasizes that learning is demonstrated when a change in behavior occurs as a result of experience [5]. Clearly, the processes that educational institutions use to grade students are experiences that will influence how they learn and show changes in their behavior. This article provides a snapshot of pass/fail and discretionary grading approaches, highlighting the advantages and disadvantages of each.

\section{Grading Practices}

\subsection{The Purpose of Grading}

Educational measurement theorist Peter Airasian defined grades as recognized symbols, the purpose of which are to provide students with feedback about their progress and achievements; to guide students in future course work; to motivate students; and to inform instructional planning [6]. Airasian also emphasized that educational systems rely on grades to determine student rankings in classes, their suitability to progress to the next level; and to graduate [6].

In higher education, grades are usually an aggregate of individual marks from a series of assignments, but they may also be determined from a single major piece of work in a course or unit [7]. In a practice discipline such as nursing, assignments often include both teacher assessment and teacher evaluation. Assessment requires teachers to make inferences about what students' know in relation to what they do, and evaluation requires teachers to make judgements about the value of what students do in relation an objective [8]. Thus, the aggregate of marks within a single grade provides a symbolic representation of overall achievement [7].

\subsection{Norm-Referencing}

Differentiating between grading practices classified as norm-referenced and those classified as criterion-referenced is a key consideration in understanding the overall grading process. Norm-referenced grading measures student achievement in comparison to peers, ranking them in relation to other students [8]. With norm-referenced grading, in any student group, only a select few will be eligible to earn top grades, most will receive mid-level grades, and at least some will receive failing grades. Norm-referenced grading is based on the symmetrical statistical model of a bell or normal distribution curve [8].

Norm-referenced grading provides programs of study with the opportunity to compare students in a particular location with national norms; to highlight assignments that are too difficult or too easy; to monitor grade distributions such as too many students receiving high or over-inflated grades; and to award scholarships to excelling students [8]. On the other hand, this grading practice is grounded in the premise that one student's achievements, successes and even failures are unfairly dependent on the performances of others [8].

\subsection{Criterion-Referencing}

Conversely, criterion-referenced grading measures do not include comparisons 
with other students. Rather, student achievement is measured in relation to predetermined criteria [8]. Therefore, all members of student groups are equally eligible to earn top, average or failing grades. The process is transparent and students can make associations between their performance and expected outcomes; and they can link their personal learning needs to opportunities for remediation [8].

Most institutions of higher learning, including those who offer nursing education, now incorporate criterion-referenced grading practices into at least some of their programs [7] [9] [10]. Traditionally, an understanding of where students were ranked in relation to others was believed to communicate useful information to employers, teachers and students; and it was considered a valuable strategy to prevent grade inflation [10]. However, for professional programs, where clear outcomes have been adopted, grades reflecting individual achievement in relation to specific criteria are equally valuable in providing this needed information [10]. Both pass/fail and discretionary grading practices are classified as criterion referenced [7].

\subsection{Subjectivity}

Subjectivity, where teachers' personal opinions and feelings impact grading, can be expected to affect grading practices in general and criterion-referenced grading practices in particular. In 1912, Starch and Elliot's classic study examining how 147 high school English teachers assigned grades to two identical student papers revealed marks ranging from $50 \%$ to $90 \%$ for the same paper [11]. Later, in 2011, Brimi replicated the study and obtained strikingly similar results in that 73 high school English teachers assigned marks from 50\% to $96 \%$ for the same paper [12].

Knowing that subjectivity is likely to occur, strategies geared towards achieving fair measurement of student achievement can be implemented. For example, double-marking, or having more than one teacher assign marks to an assignment is useful [13]. Similarly including peer assessments of student work is valuable [14] [15]. Including opportunities for self-assessment in grading practices is especially important [8] [16]. Melrose, Park and Perry caution that bias can occur in peer assessment when students are hesitant to provide critical feedback to one another and in self-assessment when students overrate their abilities [8].

\section{Historical Backdrop}

Reflecting on the history of grading provides insight into how practices in use today have evolved. Prior to the late 1800's, when few students advanced beyond elementary school, information about student progress centered on informal communication between student, teachers and parents [17].

By the 1900's, as compulsory high school attendance increased student numbers, and as more students went on to attend university, a shift to percentage grades occurred as teachers and professors accommodated this increase and responded to a need to identify student accomplishments in particular subject 
areas [17]. In the 1960's letter grades increased in popularity and remain so today [17].

Grading practices created a way to rank individual student performance, but they also provided opportunities to rank the prestige of academic institutions [18]. Critics have questioned whether grades have evolved more for the benefit of administering and promoting organizations rather than for their intended purpose of providing feedback, guidance and motivation to students [18].

\section{Pass/Fail Grading}

Pass/fail, as the name implies, provides only two options for grading students. In concert with the shift away from norm-referenced and towards criterion-referenced grading practices, many nursing education programs have incorporated pass/fail measurement of student achievement. Clinical courses are well-suited to pass/fail grading [2].

\subsection{Advantages}

Pass/fail grading is believed to exert positive influences on learning by supporting students' psychological health and wellbeing [19] [20] [21]. For example, with medical students, this approach has been found to reduce student stress and promote group cohesion [22]. It has reduced competition among students [23]. Further, a pass/fail approach reduced feelings of emotional exhaustion, depersonalization, burnout and the desire to drop out [24]. It did not decrease performance on qualifying examinations [25]. With nursing students, pass/fail grading was influential in supporting students towards providing safer care to their patients, including a reduction in medication errors [26].

The process of grading itself has been criticized for diminishing interest in learning, creating a preference for the easiest possible task, reducing the quality of thinking, increasing cheating and promoting a fear of failure [27]. Although a pass/fail approach, as a classification of grading, is not immune to these criticisms, it is considered to have a less detrimental effect on learning than discriminatory approaches.

Pass/fail grading is purported to increase students' intrinsic or internal motivation to learn. It allows them to pursue areas that are of most interest and relevance to them, rather than focusing only information that will be tested [4]. In turn, this intrinsic motivation lays a foundation for the self-direction and self-regulation required in nursing and all health care disciplines [4].

\subsection{Disadvantages}

Pass/fail grading can also exert negative influences on learning. Students who have excelled and demonstrated remarkable achievements may not be recognized or differentiated from those who simply met the requirements to pass [19]. This approach may not depict an accurate picture of the specific learning objectives that were mastered and those that need improvement [28].

Pass/fail grading can create situations where students do not perform effec- 
tively on critically important objectives, but achieve a passing grade because they have performed well on those of lesser importance [28]. Additional negative influences can include the subtle suggestion that only the bare minimum is needed to pass; a possible decline in student classroom attendance; weakening of academic performance; and a potential decrease in pass rates for regulatory licensing examinations [19] [21] [23].

\section{Discretionary Grading}

Discretionary grading, which generally uses the letters $\mathrm{F}-$ to $\mathrm{A}+$ or numerical values between $0 \%$ and $100 \%$, continues to dominate reporting systems, with letter grades the most widely used [17]. Learning institutions frequently add plusses or minuses to letter grades or pair them with percentage indicators in order to enhance their discretionary function [17] [29].

It is beyond the scope of this article to discuss the many additional variations of numbered, lettered and narrative grading scales that institutions from around the world have developed. The lack of a universally accepted approach to grading scales is an illustration of the controversy that continues to surround the processes teachers use in their efforts to measure student achievement and progress.

\subsection{Advantages}

In many instances, the advantages of discretionary grading reflect a mirror image of the disadvantages of a pass/fail approach. Rather than decreasing motivation, discretionary grading can increase students' desire to perform well academically [4]. Relationships between grades and short term learning, as well as between grades and extrinsic motivation, or motivation emanating externally from others beyond oneself, have been established [30].

Students may have a tendency to take discriminatory grading more seriously [21]. Expecting a grade can increase students' confidence not only in correct answers but also in understanding answers that are incorrect [31]. Improvement demonstrated through a higher grade can help students experience a sense of satisfaction and pride.

\subsection{Disadvantages}

The extrinsic motivation associated with discretionary grading may not serve students well after they graduate. Grades are not likely to be part of everyday nursing practice and they do not usually factor into the self-regulation required by professional governing bodies.

The inherent ranking of students in relation to one another that is often associated with discretionary grading can create hierarchical categories. Students hoping to continue their education by attending further undergraduate or graduate study programs will need to identify their grades on program applications. The pressure to achieve these grades can be daunting.

Students' social status can be affected as they strive to get grades that are 
comparable to or higher than their peers [31]. While healthy competition with peers and oneself may not be problematic, anxiety, depression and inability to absorb material can result when students become overly focused on their grades [1] [19].

Although both letter and numeric discretionary approaches provide a range of grading options, faculty tend to cluster their scores around a portion of the scale instead of utilizing the whole scale [32]. This tendency may be related to how higher education courses usually have a specific minimum pass point, often a $\mathrm{C}$ or $60 \%$. This higher pass point has been linked to clustered scores [33]. As a consequence, clustered scores do not fully meet the obligation of discriminating learning achievements among students.

\section{Conclusions}

In summary, this snapshot of pass/fail and discretionary grading practices highlighted the advantages and disadvantages of the two most commonly used educational measurement tools in nursing education today. As criterion-referenced rather than norm-referenced approaches, both seek to report student achievement in relation to pre-determined criteria. Both are considered inherently subjective.

A brief historical backdrop illustrated how these approaches have been used in different educational settings over time, with neither considered superior. Pass/ fail grading, well suited for clinical courses can complement the discriminatory grading widely used by nursing programs in higher education settings.

Pass/fail grading can promote the self-directed, intrinsically motivated learning expected in professional nursing practice and it can support students' psychological health and well-being. However, it limits opportunities for recognizing excelling students.

Discretionary grading, through the extrinsic motivator of earning a high grade, can encourage students to perform better academically. Ranking students on a range of scores between $\mathrm{F}-$ and $\mathrm{A}+$ or $0 \%$ and $100 \%$ provides a clear and recognizable symbol or illustration of their achievements, both in relation to their previous work, their peers and their program outcomes. Yet, the experience of being ranked can lead to unhealthy competition and unnecessary stress.

Despite the attention that the topic of grading students continues to receive among educators, the process is far from exacting. Elements of both pass/fail and discretionary grading have merit as nurse educators strive to fully and accurately represent student achievements. This is both a challenge and an opportunity for the field.

\section{References}

[1] Donaldson, J.H. and Gray, M. (2012) Systematic Review of Grading Practice: Is There Evidence of Grade Inflation? Nurse Education in Practice, 12, 101-114. https://doi.org/10.1016/j.nepr.2011.10.007

[2] Oermann, M.H., Yarbrough, S.S., Saewert, K.J., Ard, N. and Charasika, M. (2009) Clinical Evaluation and Grading Practices in Schools of Nursing: National Survey 
Findings Part II. Nursing Education Perspectives, 30, 352-357.

[3] Soh, K. (2011) Grade Point Average: What's Wrong and What's the Alternative? Journal of Higher Education Policy and Management, 33, 27-36. https://doi.org/10.1080/1360080X.2011.537009

[4] White, C. and Fantone, J. (2009) Pass-Fail Grading: Laying the Foundation for SelfRegulated Learning. Advances in Health Science Education, 15, 469-477. https://doi.org/10.1007/s10459-009-9211-1

[5] Cronbach, L. (1963) Educational Psychology. 2nd Edition, Harcourt, New York.

[6] Airasian, P. (1994) Classroom Assessment. 2nd Edition, McGraw Hill, New York.

[7] Sadler, R. (2005) Interpretations of Criteria-Based Assessment and Grading in Higher Education. Assessment and Evaluation in Higher Education, 30, 175-194. https://doi.org/10.1080/0260293042000264262

[8] Melrose, S., Park, C. and Perry, B. (2015) Creative Clinical Teaching in the Health Professions. http://epub-fhd.athabascau.ca/clinical-teaching/

[9] Aviles, C. (2001) Grading with Norm-Referenced or Criterion-Referenced Measurements: To Curve or Not to Curve, That Is the Question. Social Work Education, 20, 603-608. https://doi.org/10.1080/02615470120072869

[10] Lok, B., McNaught, C. and Young, K. (2015) Criterion-Referenced and Norm-Referenced Assessments: Compatibility and Complementarity. Assessment and Evaluation in Higher Education, 41, 450-465. https://doi.org/10.1080/02602938.2015.1022136

[11] Starch, D. and Elliott, E.C. (1912) Reliability of the Grading of High School Work in English. School Review, 20, 442-457. https://doi.org/10.1086/435971

[12] Brimi, H.M. (2011) Reliability of Grading High School Work in English. Practical Assessment, Research and Evaluation, 16, 1-12.

http://pareonline.net/getvn.asp? $\mathrm{v}=16 \& \mathrm{n}=17$

[13] Parington, J. (1994) Double-Marking Students' Work. Assessment and Evaluation in Higher Education, 19, 57-60. https://doi.org/10.1080/0260293940190106

[14] Hodgson, P., Chan, K. and Liu, J. (2014) Outcomes of Synergetic Peer Assessment: First-Year Experience. Assessment and Evaluation in Higher Education, 39, 168179. https://doi.org/10.1080/02602938.2013.803027

[15] McConlogue, T. (2010) But Is It Fair? Developing Students' Understanding of Grading Complex Written Work through Peer Assessment. Assessment and Evaluation in Higher Education, 37, 113-123.

https://doi.org/10.1080/02602938.2010.515010

[16] Kajander-Unkuri, S., Meretoja, R., Katajisto, J., Saarikoski, M., Salminen, L., Suhonene, R. and Leino-Kilpi, H. (2013) Self-Assessed Level of Competence of Graduating Nursing Students and Factors Related to It. Nurse Education Today, 34, 795801. https://doi.org/10.1016/j.nedt.2013.08.009

[17] Guskey, T. (2013) The Case against Percentage Grades. Educational Leadership, 71, 68-72.

https://next-generation-leadership.wikispaces.com/file/view/GUSKEY+EL13+Perce ntage+Grades.pdf

[18] Schneider, J. and Hutt, E. (2014) Making the Grade: A History of the A-F Marking Scheme. Journal of Curriculum Studies, 46, 201-224.

https://doi.org/10.1080/00220272.2013.790480

[19] Spring, L., Robillard, D., Gehlbach, L. and Simas, T. (2011) Impact of Pass/Fail Grading on Medical Students' Well-Being and Academic Outcomes. Medical Education, 45, 867-877. https://doi.org/10.1111/j.1365-2923.2011.03989.x 
[20] Yusoff, M. (2013) Associations of Pass-Fail Outcomes with Psychological Health of First-Year Medical Students in a Malaysian Medical School. Sultan Qaboos University Medical Journal, 13, 107-114. https://doi.org/10.12816/0003203

[21] Wilkinson, T. (2011) Pass/Fail Grading: Not Everything That Counts Can Be Counted. Medical Education, 45, 860-862. https://doi.org/10.1111/j.1365-2923.2011.04018.x

[22] Rohe, D., Barrier, P., Clark, M., Cook, D., Vickers, K. and Decker, P. (2006) The Benefits of Pass-Fail Grading on Stress, Mood, and Group Cohesion in Medical Students. Mayo Clinic Proceedings, 81, 1443-1448.

https://doi.org/10.4065/81.11.1443

[23] Bloodgood, R., Short, J., Jackson, J. and Martindale, J. (2009) A Change to Pass/Fail Grading in the First Two Years at One Medical School Results in Improved Psychological Well-Being. Academic Medicine, 84, 655-662. https://doi.org/10.1097/ACM.0b013e31819f6d78

[24] Reed, D., Shanafelt, T., Satele, D., Power, D., Eacker, A., Harper, W., et al. (2011) Relationship of Pass/Fail Grading and Curriculum Structure with Well-Being among Preclinical Medical Students: A Multi-Institutional Study. Academic Medicine, 86, 1367-1373. https://doi.org/10.1097/ACM.0b013e3182305d81

[25] McDuff, S., McDuff, D., Farace, J., Kelly, C., Savoia, M. and Mandel, J. (2014) Evaluating a Grading Change at UCSD School of Medicine: Pass/Fail Grading Is Associated with Decreased Performance on Preclinical Exams but Unchanged Performance on USMLE Step 1 Scores. BMC Medical Education, 14, 1-15.

[26] Tanicala, M.L., Scheffer, B.K. and Roberts, M.S. (2011) Pass/Fail Nursing Student Clinical Behaviours Phase I: Moving towards a Culture of Safety. Nursing Education Perspectives, 32, 155-161. https://doi.org/10.5480/1536-5026-32.3.155

[27] Kohn, A. (2011) The Case against Grades: When Schools Cling to Letter and Number Rating, Students Get Stuck in a System That Undermines Learning. Educational Leadership, 1, 28-33. http://www.alfiekohn.org/article/case-grades/?print=pdf

[28] Walsh, C.M. and Seldomridge, L.A. (2005) Clinical Grades: Upward Bound. Journal of Nursing Education, 44, 162-168.

[29] Barnes, K. and Buring, S. (2012) The Effect of Various Grading Scales on Student Grade Point Averages. American Journal of Pharmaceutical Education, 76, Article No. 41. https://doi.org/10.5688/ajpe76341

[30] Stan, E. (2012) The Role of Grades in Motivating Students to Learn. Procedia-Social and Behavioral Sciences, 69, 1998-2003. https://doi.org/10.1016/j.sbspro.2012.12.156

[31] Barenberg, J. and Dutke, S. (2013) Metacognitive Monitoring in University Classes: Anticipating a Graded vs. Pass-Fail Test Affects Monitoring Accuracy. Metacognition Learning, 8, 121-143. https://doi.org/10.1007/s11409-013-9098-3

[32] Isaacson, J. and Stacy, A. (2009) Rubrics for Clinical Evaluation: Objectifying the Subjective Experience. Nurse Education in Practice, 9, 134-140.

https://doi.org/10.1016/j.nepr.2008.10.015

[33] Scanlan, J. and Care, D. (2008) Issues with Grading and Grade Inflation in Nursing Education. In: Oermann, M.H., Ed., Annual Review of Nursing Education, Volume 6, Clinical Nursing Education, Springer Publishing Company, New York, 173-188. 
Submit or recommend next manuscript to SCIRP and we will provide best service for you:

Accepting pre-submission inquiries through Email, Facebook, LinkedIn, Twitter, etc. A wide selection of journals (inclusive of 9 subjects, more than 200 journals)

Providing 24-hour high-quality service

User-friendly online submission system

Fair and swift peer-review system

Efficient typesetting and proofreading procedure

Display of the result of downloads and visits, as well as the number of cited articles Maximum dissemination of your research work

Submit your manuscript at: http://papersubmission.scirp.org/

Or contact ojn@scirp.org 